\title{
Observations Suggesting Allelism of the Achondroplasia and Hypochondroplasia Genes
}

\author{
VICTOR A. McKUSICK, THADDEUS E. KELLY, and JOHN P. DORST \\ From the Division of Medical Genetics, Department of Medicine, Johns Hopkins University School of Medicine and \\ fohns Hopkins Hospital, Baltimore, Maryland 21205, USA
}

\begin{abstract}
Summary. It is argued that there are at least two alleles at the achondroplasia locus: one responsible for classic achondroplasia and one responsible for hypochondroplasia. Homozygosity for the achondroplasia gene produces a lethal skeletal dysplasia; homozygosity for hypochondroplasia has not been described. We report here a child considered to be a genetic compound for the achondroplasia and hypochondroplasia alleles.
\end{abstract}

A wide range and diversity of phenotype produced by allelic series have been demonstrated: (1) in experimental species such as the mouse in which controlled matings permit reasonable proof of allelism and (2) in man for loci such as those for the polypeptide chains of the haemoglobins where the chemistry substitutes for controlled matings in providing this proof. Genes known to be allelic because they determine structural variants of the beta haemoglobin chain produce phenotypes as disparate as cyanosis (eg, $\mathrm{Hb} \mathrm{M}$ Saskatoon, etc), polycythaemia (eg, $\mathrm{Hb}$ Chesapeake) and anaemia, either persistent with painful crises (eg, $\mathrm{Hb} \mathrm{S}$ ) or intermittent, druginduced (eg, $\mathrm{Hb} \mathrm{Zürich}$ ). The production of very different phenotypes by allelic genes seems to be illustrated further by those disorders in which functional deficiency of the same enzyme is demonstrable. (The validity of this type of evidence for allelism is examined elsewhere [McKusick, 1973].) A dramatic example is provided by the Hurler and Scheie syndromes which were previously thought to be quite separate and distinct mucopolysaccharidoses and certainly are strikingly different clinically. The fact that both have deficiency of $\alpha$-L-iduronidase suggests that each is due to homozygosity for an allele at the same locus (McKusick et al, 1972a and b).

Further phenotypic diversity is provided by genetic compounds-the condition when two different rare mutant alleles are present. Among the

Received 20 November 1972.

Supported by a Genetics Center Grant from the NIH (GM 19489) and by a grant from the National Foundation-March of Dimes. haemoglobinopathies a cardinal example is SC disease whose phenotype is distinctive from both of the homozygous states SS and CC. Compounds of the Hurler and Scheie genes are also thought to occur (McKusick et al, 1972a and b), producing a phenotype intermediate between those of the two homozygotes.

Even when the chemical nature of the mutation is not known, the phenotypic effects may allow the genetic compound to be distinguished from the state of double heterozygosity. Thus, $\beta$-thalassaemia is an 'interacting' form vis-à-vis $\mathrm{Hb} \mathrm{S}, \mathrm{Hb} C$ etc (Weatherall and Clegg, 1972). That the gene for $\beta$-thalassaemia is allelic (or pseudoallelic, ie, very closely linked) to the genes for $\mathrm{Hb} \mathrm{S}$ and $\mathrm{Hb} \mathrm{C}$ is indicated by family studies and is supported by the fact that S-beta thalassaemia is a distinctive disorder, called microdepranocytosis in the earlier literature. On the other hand, the person heterozygous for both $\alpha$-thalassaemia and sickle haemoglobin is asymptomatic.

In recent years the relative invariability of the achondroplasia phenotype has been realized, as well as the fact that many skeletal dysplasias have been mis-diagnosed achondroplasia in the past. The consistent dominant inheritance of achondroplasia is also well established. Moreover, in recent years an achondroplasia-like condition called hypochondroplasia has been delineated (Walker et al, 1971). The hypochondroplasia phenotype is more variable than the achondroplasia phenotype. Hypochondroplasia shows many of the same radiological 


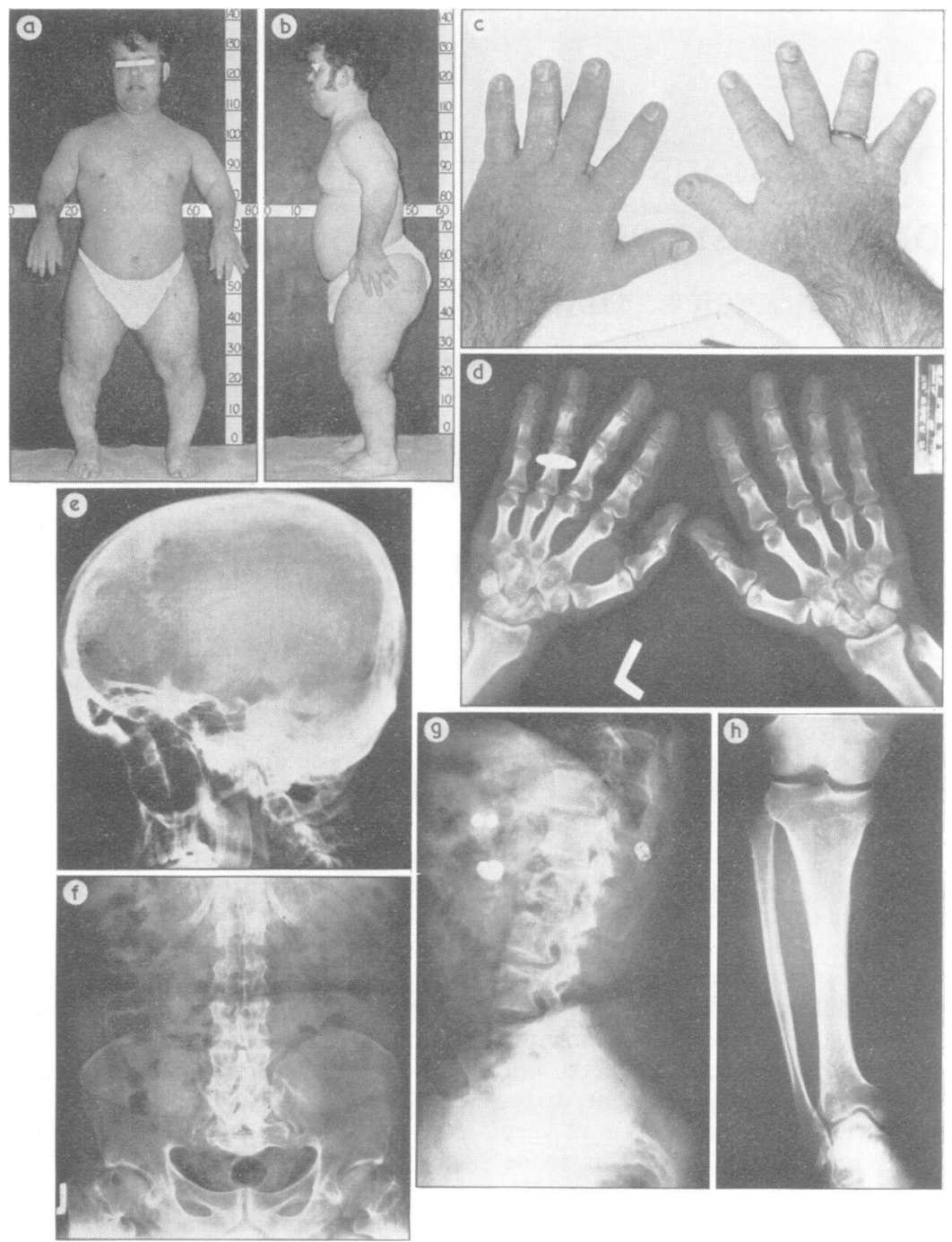

Frg. 1. Case 1. a and b: the appearance is in all ways characteristic of achondroplasia. Note bulging calvaria, depressed nasal bridge, maxillary hypoplasia, trident hand, bowed legs and, of course, dwarfism. The trident hand is more evident on the left and is created by the cleft between the third and fourth fingers. c: the photograph of the hands shows the trident configuration less in the left hand (with the ring) because the fingers are fanned out. d: on radiological examination, the cleft between the third and fourth fingers is evident bilaterally, more on the left. Bones are short and relatively wide, especially at their ends. e: $x$-ray film of the skull shows a very short chondrocranium and consequent mid-face hypoplasia. f: the radiological examination of the lumbar spine and pelvis shows a very narrow spinal canal. Because of the exaggerated lumbar lordosis, the spinal canal in the sacrum is viewed 'end on'. The pelvic inlet is quite small, caused in part by the severe hypoplasia of the body of each iliac bone. Greater sciatic notches are small and coxa vara is present. g: the great reduction in the sagittal diameter of the lumbar spinal canal results from the very short pedicles. There is marked scalloping of the posterior surfaces of the vertebral bodies. h: the fibula is excessively long, both proximally and distally, and the leg consequently is bowed.

features as achondroplasia, but they are less marked. Thus, whereas the spinal canal may show caudad narrowing as in achondroplasia, it is less severe and the skull is almost completely spared in hypochondroplasia. Hypochondroplasia is also a dominant. Within families hypochondroplasia and achondroplasia 'breed true to type'.

The grim prognosis which was earlier given for achondroplasia has required revision now that definitive diagnostic criteria applicable even in the 


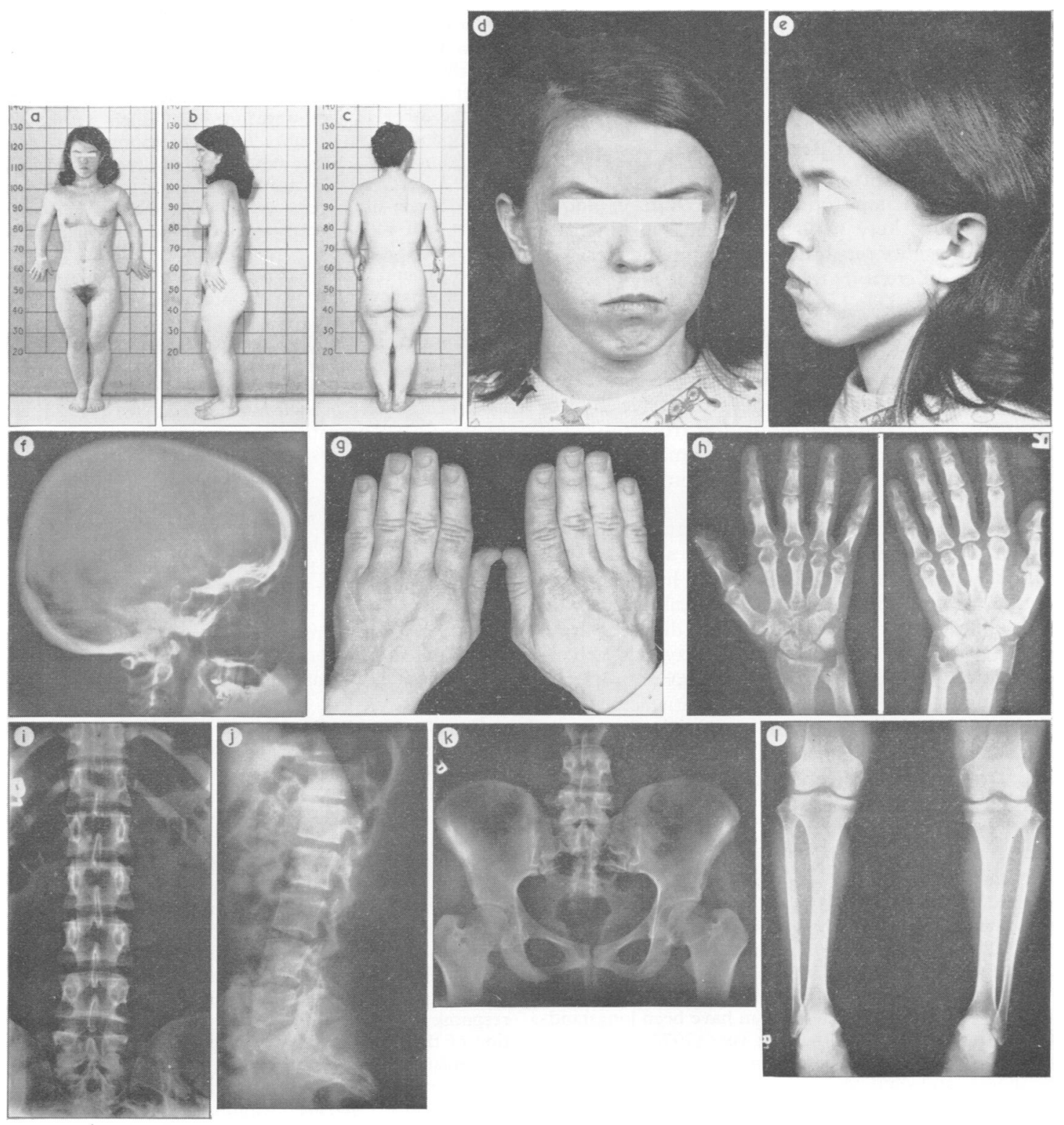

Fig. 2. Case 2. a, b, and $\mathbf{c}$ : in addition to short stature the patient demonstrates relatively straight legs and no exaggeration of lumbar lordosis. The thoracic spine is abnormally straight. $\mathbf{d}$ and e: the face shows changes only slightly suggestive of achondroplasia. The forehead is somewhat prominent and the mid face and bridge of the nose are slightly recessed, although the nasal bridge is well formed. $f$ radiograph of the skull shows a more ample chondrocranium and mid face than in Fig. 1 e. $\mathbf{g}$ and $\mathbf{h}$ : the fingers lie in parallel, with no suggestion of trident hand, by either photography $(\mathbf{g})$ or radiology $(\mathbf{h})$. The abnormalities in bone shape are similar to those in achondroplasia but less severe. i and $\mathbf{j}$ : the lumbar spinal canal narrows in the caudad portion, but less than in her husband, and only minimal scalloping is seen. $\quad k$ : the iliac bones are almost normal in shape, with only slight reduction in size of iliac bodies and greater sciatic notches. The pelvic inlet is small, but more generous than in her husband. 1: the bones of the legs are relatively gracile, compared with her husband's. The fibula is not excessively long, and there is no bowing. 
newborn are available from radiological study. Forms of skeletal dysplasia leading to early death (eg, thanatophoric dwarfism and achondrogenesis) have been separately delineated (McKusick, 1972). The heterozygous achondroplastic infant is hardy. Reduced Darwinian fitness is probably only to a limited extent the result of failure to survive to reproductive age. (In the past when rickets was frequent, leading to contracted pelvis, the large head of the achondroplast placed him in added jeopardy and there may have been some increase in early mortality resulting from traumatic birth.)

Quite a different matter, however, is homozygous achondroplasia (Hall et al, 1969), which has now been rather frequently observed because of the tendency of achondroplasts to marry each other. Neonatal death is invariable in these cases, it seems. Neurological difficulties from progressive hydrocephalus, and respiratory difficulties from restricted thoracic cage and perhaps abnormality of the tracheobronchial cartilages, are incompatible with survival of more than a few weeks.

Here we describe a 'new' skeletal phenotype which occurred in the offspring of a father with achondroplasia and a mother with hypochondroplasia. The clinical and radiological features in this child, now two years old, are different from heterozygous achondroplasia, homozygous achondroplasia, and heterozygous hypochondroplasia. The findings are considered most satisfactorily explained by allelism of the achondroplasia and hypochondroplasia genes with the child reported here representing the genetic compound state.

\section{Case Reports}

Case 1. The father, who has classic achondroplasia. M.R. (JHH 14591 40) was born 21 July 1942 to a then 18-year-old primigravida mother. His father was 20 years old. Four younger sibs are all normal. At birth, dwarfism and a large head were noted.

Early development and childhood were normal. As an adult, obesity and hypertension have been longstanding problems. During the past year (1972) he has experienced increasing problems with paresthesias, weakness, and pain in his legs when walking. These symptoms are relieved by resting in a squatting position. In the past few months after walking 40-50 yards he develops a flapping gait. This also resolves with resting.

In 1972 his height was $137 \mathrm{~cm}$ and his weight $68 \mathrm{~kg}$. $\mathrm{He}$ exhibited the typical features of achondroplasia: frontal bossing, mid-facial hypoplasia, lumbar lordosis, rhizomelic dwarfism, trident sign of the fingers, tibial bowing, and limitation of extension at the elbow (Fig. 1). A neurological evaluation has not been possible as yet.

The radiological features are typical of achondroplasia.
Case 2. The mother, who is considered to be an example of hypochondroplasia. D.R. (JHH 14586 09) was born in January 1947, of a 32-year-old mother and a 35-year-old father. The mother was $163 \mathrm{~cm}$ tall but the maternal grandfather was $185 \mathrm{~cm}$ tall. The father was $193 \mathrm{~cm}$ tall. She was the third in a sibship of 12; the other 11 sibs were normal. Birth weight was $2524 \mathrm{~g}$ and length $48 \mathrm{~cm}$. Early development was considered normal. Short stature was not recognized until about 2 years. At 6 years of age she was the same height as her 3-year-old sister. At 15 years she was $127 \mathrm{~cm}$ in height and at 18 years she achieved her final adult stature of $132 \mathrm{~cm}$.

Her general health has been good. She has had only one pregnancy, that which produced the infant described below as case 3 .

Examination (1972) showed her height to be $132 \mathrm{~cm}$ (pubis-heel $54 \mathrm{~cm}$ ) and weight $33 \mathrm{~kg}$ (see Fig. 2a-2c). Frontal bossing and hypoplasia of the mid-face with flat nasal bridge were present but minimal (see Fig. 2d, 2e). At the elbows pronation and extension were somewhat limited. The fingers lay in parallel with no suggestion of trident hand (see Fig. 2g, 2h). The normal dorsal kyphosis was almost completely lacking. The legs were short but straight. No neurological symptoms or objective deficits were elicited.

The radiological features are typical of relatively severe hypochondroplasia and different from those of achondroplasia (see Fig. 2f, 2h, and 2l). The radiographic differences from the husband are not accounted for by the sex difference (see Hall et al, 1969 for radiographic findings in a man and wife, both achondroplastic).

Case 3. The daughter who has a unique skeletal disorder and probably represents the genetic compound for achondroplasia and hypochondroplasia. S.R. (JHH 1458610 ) was born 20 December 1970 by Caesarean section. Birth weight was $3362 \mathrm{~g}$ and head circumference $40 \mathrm{~cm}$.

During the first year numerous hospitalizations were necessitated by febrile respiratory illnesses. A ventriculogram, done at the age of 2 months because of large head (circumference $42 \mathrm{~cm}$ ), showed normal pressure and mild dilatation of the ventricles. Both gas and positive contrast (Iophendylate*) were used for the ventriculogram, which was followed by an inflammatory response. Serial studies aimed at following the resolution of this inflammatory reaction were complicated by one episode of respiratory arrest with aspiration pneumonia and by subdural effusions, which resolved with repeated taps. Seizures beginning at age 4 months were controlled with dilantin and phenobarbital.

By July 1971 her head circumference was $46 \mathrm{~cm}$. She was described as a floppy infant with hyperactive reflexes. Although ventricular pressure and size were unchanged, a right ventriculojugular shunt was performed.

In March 1972 (age 15 months) examination showed head circumference $45 \mathrm{~cm}$, weight $5.8 \mathrm{~kg}$, length $60 \mathrm{~cm}$. Frontal prominence was striking with an anterior

\footnotetext{
* Pantopaque ${ }^{\circledR}$.
} 

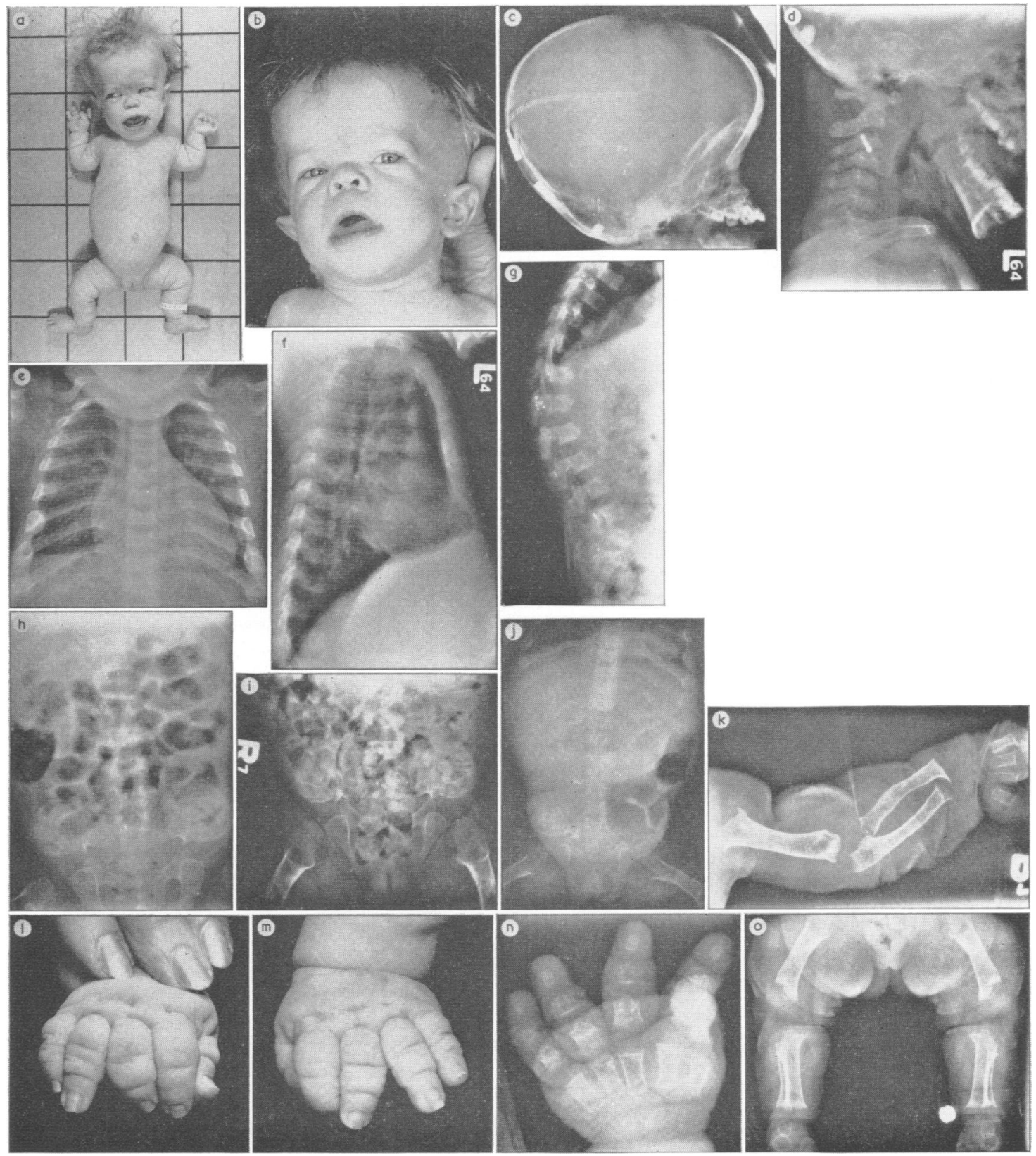

FIg. 3. The proposita, case 3. a and b: appearance at the age of 14 months. The limbs are very short and the hands, face, and cranial vault show exaggerated changes of achondroplasia. c: the verv large cranial vault and short chondrocranium are demonstrated. Mid face hypoplasia is severe. The tip of the Holter shunt tube is in the lateral ventricle. d: probable fibrous occipitalization of $\mathrm{C}-1$, a frequent finding in achondroplasia, is demonstrated on flexion of the neck. The odontoid process is seen to be short. e and $f$ : the small size of the thorax causes the heart to appear large. The shortness of the ribs is shown especially well on the lateral radiograph. g: the lumbar spine shows wide intervertebral discs, small vertebral bodies, and extremely short pedicles. $\mathbf{h}$ and $\mathbf{i}$ : the iliac wings are square and the iliac bodies very small, with consequent narrowing of the greater sciatic notches. Although only poorly seen, the spinal canal is markedly narrowed. $\mathbf{j}$ : the spine and pelvic changes are especially well shown on another examination. k: the bones of the arm are bowed and unusually short. $1, \mathbf{m}$, and $\mathbf{n}$ : in both their photographic and radiological features, the hands are a caricature of those of the child with ordinary heterozygous achondroplasia. Note especially the extreme shortening of the phalanges. o: the bones of the legs are shorter than usual in achondroplasia. (All radiographs except Fig. 3 i were taken at the age of 14-15 months.) 
fontanelle measuring $4 \times 3 \mathrm{~cm}$. Mid-facial hypoplasia was marked. Bilateral serous otitis media as well as otitis externa was demonstrated. The thorax was small and out of proportion to the rest of the trunk. Inguinal hernia was present bilaterally. Rhizomelic dwarfism, lumbar gibbus, generalized joint laxity, especially at the knees, and unusually short tapering fingers were evident. The child was too floppy to sit unsupported and had only fair head control. There was little vocalization or response to her environment. She followed a light but did not respond to a bell. She held a pacifier but did not transfer objects. Muscle tone was increased to passive movement. Reflexes were hyperactive.

Laboratory Investigations (at age 15 months) included an electroencephalogram that was considered normal for the patient's age and an echoencephalogram that showed no displacement of midline structures and normal size of lateral ventricles. On the infant Stanford-Binet test, all items at 4 months were passed, but none of those at 11 months.

Skeletal Radiographs (at age 15 months) showed small vertebral bodies with large notches for the ring apophyses. The first cervical vertebra appeared occipitalized. Although the odonotoid process of $\mathrm{C}_{2}$ was hypoplastic, no anterior subluxation was evident. The interpedunculate distance was narrow especially in the lumbar spine. The iliac wings were flared but there was virtually no body of the ilia. The greater sciatic notches were small and the roof of each acetabulum was horizontal. The long bones were short and wide with thin cortices. The metaphyses were flared and oriented obliquely. The distal femoral and proximal tibial epiphyses were very small and closely applied to the metaphyses. Wide cartilage spaces were demonstrated at the hips, knees and ankles. The metatarsals and metacarpals were short and wide with extremely short proximal phalanges. No epiphyses were ossified in the upper limbs.

The degree of bone changes is considered intermediate between those of heterozygous achondroplasia on the one hand and homozygous achondroplasia or thanatophoric dwarfism on the other. The changes, eg, those in the hand (see Fig. $3 \mathrm{k}-3 \mathrm{~m}$ ), were a caricature of those of heterozygous achondroplasia.

\section{Discussion}

On several occasions we and others have observed patients who carry two rare detrimental dominant genes (other than genes for haemoglobinopathies).

These include the following:

1. Hereditary haemorrhagic telangiectasia (18730)* and elliptocytosis (13050 or 13060).
2. Achondroplasia (10080) and neurofibromatosis (16220).

3. Achondroplasia and X-linked vitamin-Dresistant rickets (19310).

4. Neurofibromatosis (16220) and familial colonic polyposis (17510).

5. Osteogenesis imperfecta (16620) and parastremmatic dwarfism (16840).

6. Peutz-Jeghers syndrome (17520) and polycystic kidneys (17390).

7. Tuberous sclerosis (19110) and neurofibromatosis (16220).

8. Acanthosis nigricans (10060) and hereditary hemorrhagic telangiectasia (18730).

9. Neurofibromatosis (16220) and Ehlers-Danlos syndrome (1.3000).

In none of these pairs was there any suggestion of interaction of the dominant genes concerned. There was, therefore, no evidence of allelism according to the model of the 'interacting' and 'noninteracting' thalassaemias. Indeed, achondroplasia and vitamin-D-resistant rickets are necessarily non-allelic, since they are autosomal and X-linked, respectively.

\section{REFERENCES}

Hall, J. G., Dorst, J. P., Taybi, H., Scott, C. I., Langer, L. O., Jr. and McKusick, V. A. (1969). Two probable cases of homozygosity for the achondroplasia gene. In Birth Defects: Original Article Series. Clinical Delineation of Birth Defects, 5, pt 4, pp. 24-34. National Foundation-March of Dimes, New York.

McKusick, V. A. (1971). Mendelian Inheritance in Man. Autosomal Dominant, Autosomal Recessive and X-linked Phenotypes, 3rd edition. Johns Hopkins University Press, Baltimore.

McKusick, V. A. (1972). Disorders of the osseous skeleton. In Heritable Disorders of Connective Tissue, 4th edition, chapter 13. C. V. Mosby, St Louis.

McKusick, V. A. (1973). Phenotypic diversity of human disease resulting from allelic series. American fournal of Human Genetics. (In press.)

McKuisick, V. A., Howell, R. R., Hussels, I. E., Neufeld, E. F., and Stevenson, R. E. (1972a). Allelism, non-allelism and genetic compounds among the mucopolysaccaridoses. Lancet, 1, 993996.

McKuisick, V. A., Howell, R. R., Hussels, I. E., Neufeld, E. F., and Stevenson, R. E. (1972b). Allelism, non-allelism and genetic compounds among the mucopolysaccharidosis: corrective factors in nosology. Transactions of the Association of American Physicians. (In press.)

Walker, B. A., Murdoch, J. L., McKusick, V. A., Langer, L. O., and Beals, R. K. (1971). Hypochondroplasia. American fournal of Diseases of Children, 122, 95-104.

Weatherall, D. J. and Clegg, J. B. (1972). The Thalassaemia Syndromes, 2nd edition. Blackwell Scientific Publications, Oxford.

* The five-digit numbers are those assigned to these phenotypes in Mendelian Inheritance in Man (McKusick, 1971). 